\title{
INTERSECÇÕES BRASIL-NIGÉRIA: A REPRESENTAÇÃO DA MATERNIDADE NAS OBRAS UM DEFEITO DE COR E THE JOYS OF MOTHERHOOD
}

\author{
CONNECTIONS BETWEEN BRAZIL AND NIGERIA: THE \\ REPRESENTATION OF MOTHERHOOD IN UM DEFEITO DE COR \\ AND THE JOYS OF MOTHERHOOD
}

Danielle de Luna e SILVA ${ }^{1}$

Maria Elizabeth P. SOUTO MAIOR ${ }^{2}$

\begin{abstract}
Resumo: A partir de estudos transnacionais (DAVIES, 1986) de feminismos africanos (NNAEMEKA, 1997; OYEWUMI, 1999) e de estudos interseccionais (HOOKS, 1984; HILL-COLLINS, 2002), o presente trabalho tem como objetivo uma análise comparativa da representação da maternidade negra em dois contextos distintos - Brasil e Nigéria - especificamente nas obras Um defeito de cor e The Joys of Motherhood, das escritoras Ana Maria Gonçalves (1970) e Buchi Emecheta (1944-2017). Nas respectivas obras, são narradas trajetórias de personagens femininas - Kehinde e Nnu Ego -, ambas inseridas em um contexto que vinculava a figura da mãe ao exercício de um ideal cultural monolítico, o da maternidade abnegada. As autoras problematizam tal construto cultural, oferecendo representações que confrontam e ressignificam a própria ideia do que seria o amor materno, em contextos de exploração escravagista, no caso de Kehinde, e de experiência colonial, em se tratando de Nnu Ego. Assim, Gonçalves e Emecheta desvelam novas possibilidades de representar e vivenciar a maternidade negra, realçando fatores como autonomia, cosmologia africana, agência e resistência. Embora ambas as escritoras escrevam a partir de contextos e continentes distintos, suas narrativas parecem oferecer uma desconstrução da representação da maternidade e das práticas de maternagem.
\end{abstract}

Palavras-chave: Maternidade. Maternagem. Buchi Emecheta. Ana Maria Gonçalves.

\begin{abstract}
From the perspective of transnational studies (DAVIES, 1986) of African feminisms (NNAEMEKA, 1997; OYEWUMI, 1999), and of intersectional studies (HOOKS, 1984; HILLCOLLINS, 2002), the present study aims at a comparative analysis of black motherhood in two different contexts - Brazil and Nigeria -, more specifically in the works Um defeito de cor and The Joys of Motherhood, by writers Ana Maria Gonçalves (1970) and Buchi Emecheta (1944-2017). In the aforementioned novels, the lives of two female protagonists - Kehinde and Nnu Ego - are narrated, both inserted within a context which associated the mother figure with the exercise of a monolithic cultural construct, one revolving around the ideal of selfless motherhood. The female writers problematize such ideal, offering representations that confront and ressignify the idea of motherly love itself, in contexts of slave exploitation, in the case of Kehinde, and of the colonial experience, as far as Nnu Ego is concerned. In this way, Gonçalves and Emecheta unveil new possibilities of representing and living black motherhood, highlighting factors such as autonomy, African cosmology, agency and resistance. Although both novelists write from distinct contexts and continents, their narratives seem to offer a deconstructed notion of motherhood and mothering practices.
\end{abstract}

\footnotetext{
${ }^{1}$ Doutora em Letras pela Universidade Federal da Paraíba (Brasil); Professora Adjunta da mesma universidade. danilunas@yahoo.com.br

${ }^{2}$ Doutora em Letras pela Universidade Federal da Paraíba; Professora Adjunta da mesma universidade. mepsm@ hotmail.com
} 
Key Words: Motherhood. Mothering. Buchi Emecheta. Ana Maria Gonçalves.

Pensar Brasil e Nigéria a partir de uma perspectiva transnacional e interseccional justifica-se pela constatação de confluências históricas e culturais, como o grande fluxo de escravizados entre Brasil e o Golfo do Benim ${ }^{3}$, durante os séculos XVII-XVIII, o que estabeleceu uma intensa troca cultural e econômica entre as duas regiões. Entre 1770 e 1850, um número significativo de falantes de Yoruba foram trazidos ao Brasil, o que explicaria, segundo a pesquisadora Ana Lúcia Araújo (2010), a presença e a continuidade de vários traços culturais e religiosos Yoruba, principalmente na Bahia ${ }^{4}$. Assim como Hill-Collins (2002) e Davies $(2003$; 1995; 1986), propomos uma leitura transnacional e translocal da experiência feminina negra afro-diaspórica, que se justifica não por considerar essa experiência como um bloco homogêneo, a-histórico e fixo; mas, pelo contrário, pelo fato de que esta perspectiva considera as especificidades dessas vivências ao mesmo tempo que aponta para confluências e conexões que transcenderiam barreiras espaciais e temporais.

Além dos aspectos acima, é preciso ressaltar que o processo de tentativa de apropriação e controle dos corpos femininos negros, particularmente no que tange à maternidade, esteve presente tanto no Brasil quanto na região do Golfo do Benim, fato que encontra reverberações tanto em Um Defeito de Cor quanto em The Joys of Motherhood. Uma análise interseccional, como a que propomos aqui, deve levar em consideração tanto as confluências quanto as particularidades dessa objetificação do corpo feminino negro, assim como os esforços das protagonistas destes romances para subverter este processo e vivenciar uma maternidade que, seja por fatores culturais, históricos ou econômicos, precisa se contrapor ao ideal de maternidade abnegada e feliz que, de certa forma, ainda permeia nosso imaginário.

Muito comumente, quando se discute maternidade, parte-se de uma visão eurocêntrica do termo. A narrativa costuma indicar como a vivência da maternidade aprisiona(va) as mulheres (em sua maior parte, brancas, e de classe média) à esfera privada ${ }^{5}$. O feminismo, assim como a revolução sexual, contrapunha-se a esse modelo que oprimia e aprisionava as mães, e a maternidade passou a ser discutida e problematizada por feministas e ativistas. Dessa forma,

\footnotetext{
${ }^{3}$ Golfo que se estende ao longo da costa da África Ocidental, indo de Gana à Nigéria.

${ }^{4}$ Além do Yoruba, várias outras etnias estão presentes na Nigéria. Apesar de pertencer aos Igbo, Buchi Emecheta estava muito familiarizada com a cultura Yoruba, o que pode ser verificado pela recorrência, em suas narrativas, de nomes utilizados nesta cultura para nomear gêmeos - Kehinde e Taiwo (BROWN-GUILLORY, 2006).

${ }^{5}$ Para uma discussão detalhada sobre gênero e suas relações com as esferas públicas e privadas, ver Okin (2008), que problematiza esta distinção e chama atenção para a importância da família dentro da política do feminismo.

Revista Graphos, vol. 21, n² 2, 2019| UFPB/PPGL | ISSN 1516-1536
} 
parte considerável do discurso feminista a partir de 1960 empenhou-se em fazer críticas à instituição da maternidade.

Um exemplo deste discurso sobre a maternidade pode ser encontrado em um importante artigo da psicanalista e filósofa estadunidense Jane Flax (1978), que discute as relações entre mães e filhas e o conflito feminino entre ser cuidada/cuidar (associado à figura materna) e estabelecer-se como um sujeito autônomo (vinculado à figura paterna) ${ }^{6}$. Não obstante Flax (1978) evidencie que escreve a partir de sua experiência e de seus pacientes - brancos e de classe média -, ao afirmar que as famílias da classe trabalhadora emulam a estrutura patriarcal das classes mais abastadas, a filósofa, contudo, parte do princípio de que todas as famílias da classe trabalhadora seguiriam a mesma organização, desconsiderando a diversidade de núcleos familiares de migrantes, latinos e afrodescendentes. A partir de uma leitura ancorada na psicanálise, ela aponta a necessidade feminina de ser cuidada e protegida (nurturance), que advém de uma experiência diferenciada gerada a partir de um desequilíbrio na maneira como mães cuidam de meninos e meninas. Os primeiros passariam pela experiência da simbiose, fase na qual o bebê não distingue a diferença entre ele e mãe, de forma mais completa e bemsucedida, ao contrário das meninas, que, por várias questões, desde traumas e conflitos advindos da relação entre as mães e suas progenitoras, até homofobia, segundo Flax, têm "mais chances de não ter tido uma experiência de simbiose adequada"7 (1978, p. 178). Ainda de acordo com a psicanalista, esse desejo feminino por cuidado e proteção, que se prolongaria durante a vida adulta, é o que teria influenciado Freud a afirmar que as mulheres buscam a mãe em seus maridos. Porém, este ponto de vista, além de evidenciar apenas um formato de estrutura patriarcal, que não leva em questão raça ou classe, acaba reforçando um padrão familiar heteronormativo.

Por outro lado, Jane Flax (1978) reconhece que as próprias relações entre mulheres, estabelecendo redes de apoio, por exemplo, seriam uma possível solução para lidar com esse desejo por proteção e para integrar este desejo de ser cuidada com o desejo de ser autônoma. O artigo, escrito no fim da década de setenta do século passado, menciona a euforia causada pela ideia de sororidade feminina, ao passo que admite as dificuldades de estabelecerem relações de irmandade entre um grupo tão heterogêneo e da dificuldade de muitas mulheres em se reconhecerem como opressoras. O que esta última afirmação parece desconsiderar são outras vivências da maternidade, como aquela experienciada por mulheres negras, de classes sociais

\footnotetext{
${ }^{6}$ Em inglês, os termos usados são: nurturance e autonomy, respectivamente.

${ }^{7}$ Tradução do trecho "(...) she is less likely to have had an adequate symbiotic experience" (FLAX, 1978, p.178). Revista Graphos, vol. 21, n² 2, 2019 | UFPB/PPGL | ISSN 1516-1536
} 
mais baixas, ou pertencentes a grupos não-hegemônicos. Contudo, é preciso pensar como a relação entre público e privado e como as relações entre homens e mulheres se estabelecem e se estabeleceram em outros contextos: em tribos, comunidades negras, favelas, quilombos, confrarias, irmandades, terreiros, igrejas etc. Em busca desta diversidade e das interseções das experiências da maternidade retratadas em narrativas escritas por mulheres negras, apresentaremos, a seguir, apontamentos sobre a experiência feminina afro-diaspórica, especificamente nos Estados Unidos, Brasil e em países africanos, como Benim e Nigéria.

Nos Estados Unidos, pesquisadoras como Bell Hooks (1992; 1984), Hortense Spillers (2000), Barbara Christian (1985), Angela Davis (1983) e Patricia Hill-Collins (2002) defendem e apontam as particularidades da maternidade negra naquele país. Suas reflexões discutem desde a apropriação do corpo feminino negro como meio de (re)produção e a fratura causada pela escravidão nas famílias negras, até a patologização desta unidade familiar, que, em sua maioria, é constituída por famílias monoparentais, chefiadas por mulheres. Hill-Collins (2002), especialmente, articula que, para a comunidade negra, a maternidade configura-se como lócus de empoderamento, e não de opressão. Estratégias como othermothering (maternidade transferida/compartilhada) ${ }^{8}$ e a importância da maternidade para a transmissão cultural e sobrevivência da comunidade ganham proeminência no pensamento da socióloga, em detrimento de uma visão da maternidade como opressora.

No Brasil, em consonância com as ideias apresentadas acima, escritoras como Sueli Carneiro (2003) e Conceição Evaristo (2005) ressaltam que, para as mulheres afro-brasileiras, a necessidade de maternar e trabalhar (ou ser forçada a trabalhar) ocorria concomitantemente. Ademais, a família constituiu-se como forma de resistência, não de controle ou opressão. Sobre as relações entre maternagem, resistência e sobrevivência, Conceição Evaristo afirma

\footnotetext{
Assim como a centelha da criação dos mais velhos se propagou anônima e oralmente até as mais novas, e nas condições de vida das mães e das avós pode se encontrar a gênese da arte literária das mulheres negras americanas da contemporaneidade, outras heranças foram conservadas no interior do grupo. Táticas de sobrevivência foram também ensinadas e aprendidas na teia familiar de todos os povos da diáspora africana. Movimentos de resistência foram executados por grupos, ou às vezes até por um indivíduo, em toda a América compondo um repertório significativo de uma história que a história não registra (2005, p. 207, grifo nosso).
}

\footnotetext{
${ }^{8}$ Podemos definir othermothering como a maternagem exercida por alguém que não possui, necessariamente, vínculos consanguíneos com a criança, podendo também ser praticada por diversos membros da família, como avós, tias, entre outros. Dessa maneira, "[a] criança nascida receberá princípios e educação de várias mulheres, suas iniciadoras. Essa é a formação natural da criança negra quando a família vai além da fronteira da consanguinidade e a imagem da mulher se fixa representando a orientadora e a responsável pela formação da família" (MELO NASCIMENTO, 2008, p. 53).
} 
Se a associação entre maternagem e empoderamento vincula, em certa medida, a experiência negra estadunidense à brasileira, é preciso apontar algumas das especificidades da maternagem afro-brasileira. No contexto nacional, em muitos casos, a prática de othermothering, assim como o próprio conceito de família, amplia-se ao abranger laços de fraternidade espirituais e religiosos, como no caso das religiões de matriz africana, que incluiria figuras como o pai de santo, mãe de santo e irmão de santo, além dos arquétipos maternos presentes em orixás como Iemanjá e Oxum. O mesmo acontece com elementos da tradição religiosa católica, ainda muito arraigados no Brasil, como a participação ativa de madrinhas e padrinhos na educação das crianças e na devoção à Nossa Senhora, denominada muitas vezes de mãezinha do céu e nossa mãe. Desta forma, na citação anterior, quando Evaristo (2005) menciona uma "teia familiar", amplia-se o conceito de unidade familiar, incluindo além de vínculos consanguíneos, os culturais e religiosos, ainda tão presentes e relevantes na sociedade brasileira.

No contexto africano, ser mãe significa a realização de um sonho acalentado ao longo da vida. Ao invés de desempoderar, a maternidade pode dar sentido à mulher e possibilita que esta encontre nela significado uma vez que, ao se tornar potente fonte de vida, torna-se também perpetuadora de sua raça, multiplicadora de grandes homens. Altamente ambígua ${ }^{9}$, uma vez que ainda atrela a mulher ao papel de nutriz, embora nem sempre à esfera doméstica, a maternidade em muitas culturas africanas abre espaço para o desenvolvimento de cadeias de solidariedade, que, aliadas à poligamia, permitem uma participação feminina ativa na atividade econômica. Concordando com essa perspectiva, a nigeriana Oyeronké Oyewumi (1999, p. 13) aponta que:

\footnotetext{
Não importa se uma sociedade africana específica demonstra um sistema de filiação patri ou matrilinear, as mães são o sustentáculo essencial dos relacionamentos sociais, das identidades e certamente da sociedade. Devido ao fato de as mães simbolizarem laços familiares, amor e lealdade incondicionais, a maternidade é invocada até mesmo em situações extrafamiliares que exigem aqueles valores. ${ }^{10}$
}

\footnotetext{
${ }^{9}$ Para um debate acerca da maternidade enquanto construto social imposto e enquanto meio de construir redes de solidariedade e agência femininas no continente africano, ver MENDES, 2017, p. 47.

${ }^{10}$ Citação original: "Regardless of whether a particular African society displays a patrilinear or matrilinear kinship system, mothers are the essential building block of social relationships, identities and indeed society. Because mothers symbolize familial ties, unconditional love and loyalty, motherhood is invoked even in extrafamiliar situations that calls (sic) upon those values" (OYEWUMI, 1999, p. 13).
} 
Não se pode, assim, dissociar a literatura africana dessa força motriz que é a maternidade enquanto temática, uma vez que inúmeros textos literários de autores e autoras da África anglófona, lusófona e francófona não só aludem a, mas problematizam esse papel social imposto às mulheres, trazendo inúmeras possibilidades de ruptura e questionamento. Segundo Carole Boyce Davies (1986), o colonialismo europeu, combinado às atitudes tradicionais excludentes para com as mulheres africanas, importou um modo de ver a mulher como cidadã de segunda classe. $\mathrm{O}$ aspecto mais preponderante da teoria africana escrita por mulheres é a negação de que sua sociedade, desde os primórdios, não tenha sido feminista. Um outro traço desta episteme é a crítica feita à perspectiva monolítica do feminismo ocidental sobre a suposta pobreza e analfabetismo da mulher daquele continente, rodeada de inúmeros filhos e impossibilitada de pensar ou agir por si só, necessitando, assim, do resgate das mulheres ocidentais. Sobre a dissociação entre maternidade e poder comumente divulgada pela teoria feminista ocidental, Nnaemeka (1997, p. 167) sugere:

É compreensível que o feminismo, que fez a questão da escolha o epicentro de sua teoria e ativismo, reluta por aceitar que a mesma questão exerça um papel preponderante em sua análise das vidas das mulheres africanas. A persistência infeliz dos argumentos feministas centrados na pressuposição de que as mulheres africanas estejam demasiado sofridas para serem capazes de tomar suas próprias decisões constitui-se em um obstáculo para o engajamento genuíno e a colaboração significativa $(\ldots)^{11}$.

Observa-se, mais uma vez, que não há uma única perspectiva teórica que dê conta de todas as nuances da experiência da maternidade de modo genérico, sendo necessário uma análise cuidadosa dos fatores que contribuem para as diferentes vivências das práticas de maternagem. A partir de tal reflexão, portanto, tornar-se-ia possível um diálogo com as ideias defendidas por Nnaemeka e Oyewumi, uma vez que não identificam, em África, uma relação dicotômica natural ou óbvia entre maternagem e trabalho, sobrevivência e poder. Assim, negam que seja a maternidade a causa preponderante para o enfraquecimento ou desempoderamento da mulher, e atribuem tal situação de desprestígio a outros fatores, tais como a escassez de recursos, o desamparo social, a extrema pobreza e a falta de representatividade política, tão presentes desde a colonização no continente africano.

\footnotetext{
${ }^{11}$ Citação original: "It is troubling but understandable, that feminism, which has made the issue of choice the centerpiece of its theorizing and activism, is reluctant to factor the same issue in its analysis of African women's lives. The unfortunate persistence of feminist arguments premised on the assumption that African women are too downtrodden to be capable of making their own choices and decisions constitutes a stumbling block to genuine engagement and meaningful collaboration...." (NNAEMEKA, 1997, p. 167).
} 


\section{Maternidade e maternagem em Um defeito de cor e The Joys of motherhood: expectativas e possibilidades}

O conceito de maternagem ou práticas de maternagem que utilizaremos aqui apoia-se nos estudos recentes sobre maternidade de Andrea O'Reilly. O termo, inspirado em escritos de Adrienne Rich (1995), diferencia maternidade como algo imposto (instituição de controle patriarcal) da experiência de protagonismo e agência da maternagem. Enquanto maternidade remete a algo estático, condicionado e controlado, a maternagem reflete agência, ação. Em $O f$ woman born, publicado em 1976, Rich define a maternagem como "a relação potencial de qualquer mulher com o seu poder reprodutivo e filhos" 12 (1995, p. 13, grifo do autor). Para Rich, a instituição da maternidade contribuiu para uma separação entre as esferas pública e privada, além de ter restringido as potencialidades das mulheres. Ao vislumbrar a possibilidade de práticas de maternagem dissociadas do controle patriarcal, Rich contrapõe-se a um discurso de repúdio à maternidade produzido nas décadas de 1950 e 1960 por Betty Friedman, Simone de Beauvoir, entre outras feministas.

Andrea O'Reilly, que em 2006, propôs o termo "motherhood studies", ressalta que "[d]entro dos estudos da maternidade, este termo é usado para significar a instituição patriarcal, ao passo que "maternagem" refere-se às experiências de maternagem vividas pelas mulheres à medida que buscam resistir à ideologia opressiva e patriarcal da maternidade" (O'Reilly, 2010: 369-370) ${ }^{13}$. É sob esta perspectiva que considera a maternagem como experiência relacional e contextual, continuamente em construção, que utilizaremos o termo neste artigo para indicar as ações e vivências das protagonistas que revelam seu agenciamento e esforços para inseriremse como sujeitos maternos dentro de instituições patriarcais, racistas e sexistas que as veem como objetos ou como seres estáticos, meramente a serviço de outros.

No caso de The Joys of Motherhood, quinto romance da nigeriana Buchi Emecheta, publicado em 1976, a expectativa de Nnu Ego é que a experiência da maternidade traga amparo na velhice. As forças de opressão e de conflito não estão relacionadas ao fato de ser mãe, no sentido de que a experiência não é temida ou criticada pela protagonista, Nnu Ego. Pelo contrário, é ansiada e desejada. Obter o respeito dado às mulheres que geram filhos, além de

\footnotetext{
12 Tradução livre do trecho "potential relationship of any woman to her power of reproductions and to children" (Rich, 1995: 13, grifo do autor).

13 Tradução livre do trecho: "Within motherhood studies the term "motherhood" is used to signify the patriarchal institution of motherhood, while "mothering" refers to women's lived experiences of mothering as they seek to resist the patriarchal of motherhood and its oppressive ideology" (O'Reilly, 2010: 369-370).
}

Revista Graphos, vol. 21, n², 2019 | UFPB/PPGL | ISSN 1516-1536 
ser lembrada e de ter alguém para chamar de "seu", são fatores determinantes na busca da personagem pelas "alegrias da maternidade". Por isso, a personagem "tinha certeza [...] de que a sua velhice seria feliz, de que, quando morresse, iria haver alguém que ficasse com ela e que a chamasse de mãe"14 (EMECHETA, 2008, p. 57). Infelizmente, apesar de todos os esforços que empreendeu para ser cuidada e protegida nos últimos anos de sua vida, ela morre só, longe dos filhos: "Nnu Ego deitou no acostamento, pensando que tinha chegado em casa. Ela morreu pacificamente ali, sem nenhum filho para segurar sua mão e nenhum amigo com quem conversar $^{15 "}$ ((EMECHETA, 2008, p. 253).

Corolariamente, as expectativas de Kehinde, protagonista de Um Defeito de Cor, segundo romance da brasileira Ana Maria Gonçalves, lançado em 2006, também são frustradas. Órfã trazida à força de Daomé (hoje chamado de Benim) para ser vendida como escrava no Brasil, no início do século XIX, imaginava poder ter o direito sobre o próprio corpo, mesmo na condição de escravizada em que se encontrava. Assim que entra na puberdade, recebe os seguintes conselhos de uma das companheiras de cativeiro:

\begin{abstract}
À noite, a Ignácia passou a mão sobre a minha cabeça e disse que eu não era mais uma menina, que já tinha corpo de mulher, e perguntou se meu sangue já tinha aparecido. Eu disse que sim, que eu tinha perguntado a Felicidade o que fazer, e que também já sabia como agir para não ficar pejada, caso fosse me deitar com homem, mas que eu ainda não sentia vontade. Naquele dia eu não entendi o motivo da pressa, mas ela comentou que, se fosse eu, começaria a pensar nisso, para que desse tempo de pelo menos escolher o primeiro (GONÇALVES, 2009, p. 151).
\end{abstract}

Porém, pouco tempo depois, Kehinde é estuprada pelo sinhô José Carlos, e desse ato de violência nasce o seu primeiro filho - Banjokô. Diferente do que imaginara, Kehinde não pode escolher o primeiro parceiro sexual, contudo, apesar do sofrimento decorrente do abuso, é a ideia de gerar uma nova vida que a impulsiona. O desejo de "pelo menos tentar fazer a própria vida [da criança que esperava] ser melhor do que a minha" (GONÇALVES, 2009, p. 173), reacende o desejo por liberdade e a esperança em dias melhores, tornando-se a força motriz de parte considerável das transformações que ocorrem na vida da protagonista. Ao tornar-se escrava de ganho, vendendo cookies ingleses em um tabuleiro pelas ruas de Salvador, Kehinde inicia uma trajetória de empreendedorismo que caminha lado a lado com a vivência da maternidade.

\footnotetext{
${ }^{14}$ Tradução livre do trecho:" She was now sure [...] that her old age would be happy, that when she died there would be somebody left behind to refer to her as "mother" (EMECHETA, 2008, p. 57).

${ }^{15}$ Tradução livre do trecho: "She died quietly there, with no child to hold her hand and no friend to talk to her." (ibidem, p. 253).
} 
Similarmente, a protagonista do romance de Emecheta, que parte de Ibuza, vilarejo rural, para Lagos, capital da Nigéria, exerce também uma atividade econômica que garante o sustento das necessidades básicas de sua família. Kehinde e Nnu Ego, buscam, portanto, autonomia financeira e se recusam a aquiescer às expectativas culturais do meio circundante quando travam uma batalha incessante para que seus filhos não enfrentem necessidades, garantindolhes um mínimo de conforto através de seus esforços de inserção no mercado de trabalho informal com um certo grau de autonomia. Assim, o empreendedorismo de Nnu Ego, que inicia um pequeno negócio vendendo cigarros (muitas vezes com o bebê em suas costas), e de Kehinde, comercializando cookies (que a afastava por semanas de seu filho), as tornam seres ativos e capazes de sobreviver em um meio adverso que tantas vezes exclui as mulheres da cadeia econômica, da participação nos lucros e do acúmulo de bens. A voz narrativa apresenta o espírito empreendedor de Nnu Ego da seguinte maneira:

\begin{abstract}
Assim que Nnaife saía pela manhã para ir ao compound do Dr Meers, ela dava banho no bebê, o colocava nas costas e se apressava para pegar os trabalhadores cedo da manhã a caminho para o trabalho. Eles compravam muitos fósforos e cigarros dela. [...] À tarde seu marido chegava do trabalho, e mais tarde ela colocava o bebê nas costas mais uma vez a tempo para a procissão de trabalhadores noturnos ${ }^{16}$ (EMECHETA, 2008, p. 57)
\end{abstract}

Já Kehinde chega a desenvolver várias outras atividades comerciais após a venda de cookies, venda esta que paga pela sua liberdade, todas podendo ser lidas como marcadores desse desejo incessante de emancipação e independência financeira:

\begin{abstract}
É interessante como algumas coisas aparecem na vida da gente na hora em que mais precisamos, e aquele vestido me remeteu à promessa que eu tinha feito quando o vi, de um dia ter muito dinheiro para andar vestida como as sinhás. Eu já tinha bastante, mas não o suficiente para gastar com roupas luxuosas e coisas assim, e preferia guardar para garantir o futuro de Banjokô, mas achei que precisava dar um jeito de ganhar muito mais. Pensei bastante por alguns dias antes de conversar como Alberto, e ele aprovou a minha ideia de montar uma padaria, o que facilitaria a fabricação dos cookies e abriria a possibilidade de ganhar dinheiro com outros produtos (GONÇALVES, 2009, p. 362).
\end{abstract}

Assim, fica evidente que tanto Nnu Ego quanto Kehinde se destacam pelo empreendedorismo, ao passo em que se distanciam do papel exclusivo normalmente esperado para elas - o de mãe e nutriz, uma vez que recusam a permanecer em seus lares para se dedicar

\footnotetext{
${ }^{16}$ Tradução livre do trecho: "As soon as Nnaife left in the mornings to go to Dr Meers's compound, she would wash her baby, put him on her back and rush to catch the early workers on their way to work" (EMECHETA, 2008, p. 57).
} 
unicamente à maternagem. Todavia, por melhor que seja beneficiar a si e aos seus com os frutos do trabalho, no caso das personagens em questão, isso não é tido como uma forma de libertação da prisão do lar. Para Kehinde, independente da maternidade, o trabalho forçado seria parte natural de sua vida. Nnu Ego também vislumbra, por um momento, desenvolver sua atividade econômica longe de casa, mas tem seu desejo tolhido pelo marido, mesmo que seja oriunda de uma sociedade rural na qual as mulheres costumavam se dedicar ao comércio. Em Ibuza, onde vivia antes de casar, Nnu Ego podia contar com uma rede de apoio de outras mulheres, que possibilitava o trânsito entre a esfera doméstica e a do trabalho. No entanto, na sociedade urbana de Lagos, tais redes de solidariedade feminina se diluem e a protagonista se vê sozinha para criar seus filhos na ausência do marido Nnaife, um lavador de roupas que exerce sua atividade na casa de um casal de britânicos, em pleno contexto da colonização da Nigéria por aquele povo.

Para as duas personagens, assim como para milhares de mulheres ao redor do globo, trabalho e maternagem caminham juntos. Mesmo que não estivessem atendendo as necessidades imediatas de seus filhos (um dos pré-requisitos para uma suposta boa maternidade), no caso de Kehinde, pelos longos períodos de ausência e, no caso de Nnu Ego, pelas longas horas que seu bebê era mantido junto à mãe enquanto os seis outros ficavam desassistidos e sozinhos em casa, estas mulheres acreditavam estar investindo não apenas no seu, como também no futuro das crianças. Kehinde acalentava o sonho de comprar a sua liberdade, enquanto Nnu Ego buscava o sustento de sua família e a segurança financeira dos filhos. Apesar de impossibilitada de obter qualquer suporte financeiro do cônjuge, Nnu Ego obtém sucesso, uma vez que consegue dinheiro suficiente para enviar os filhos homens para estudar na Inglaterra, enquanto as filhas, como de costume na cultura nigeriana, pelo menos garantiriam um bom casamento, prova incontestável dos diferentes destinos que cabiam a homens e mulheres. Verificamos, portanto, que a maternagem de mulheres negras, no caso de Kehinde e Nnu Ego, é voltada para a sobrevivência de seus filhos. É isso que ambas buscavam, apesar de percorrerem caminhos distintos.

No entanto, quando focamos a atenção específica em Nnu Ego, o reconhecimento de seus esforços para garantir que seus filhos sobrevivessem, apesar da miséria circundante, e o sonhado amparo financeiro na velhice, tão acalentado pela protagonista ao longo de toda a vida, não ocorre. A personagem morre, desamparada e esquecida, mas se vinga ao garantir que jamais concederá o dom da maternidade a qualquer mulher que orasse a ela com o intuito de realizar tal desejo. 
Quando seus filhos souberam de sua repentina morte, todos eles, até Oshia, retornaram para casa. Todos lamentaram que ela houvesse morrido antes de estarem em uma posição de dar à mãe uma boa vida. Ela teve o segundo mais caro e barulhento funeral que Ibuza havia visto e um santuário foi feito em seu nome, a fim de que suas netas pudessem apelar para ela caso fossem estéreis" (EMECHETA, 2008, p. 253).

Para compreender a dimensão e os motivos da recusa de Nnu Ego, após sua morte, em atender o desejo da fertilidade de seus descendentes, é preciso retomar uma das questões centrais do romance, denominada pela crítica Stéphane Robolin (2004) de gendered haunting, isto é, uma perseguição sobrenatural que acomete de forma específica um gênero, no caso do romance, as mulheres. As agruras de Nnu Ego são interpretadas, pelos personagens da narrativa, como sendo decorrentes da vingança de uma escrava que fora assassinada por sua família. Antes de morrer, a jovem amaldiçoou os responsáveis por sua morte, e prometeu retornar, na condição de filha legítima de Agbadi, pai da protagonista.

\begin{abstract}
Enquanto caminhava, dor e raiva travavam um combate dentro dela, às vezes a raiva parecia ser a vencedora, mas a dor emocional sempre ganhava. E era justamente esta que ela queria eliminar, muito, muito rapidamente. Logo, ela estaria lá, foi o que Nnu Ego disse a si mesma. Tudo estaria acabado em breve, bem ali, embaixo das águas profundas que corriam sob a Ponte Carter. Então ela poderia buscar e encontrar o seu chi, o seu deus pessoal, e ela perguntaria a ela o porquê de ter sido punida daquela forma. Ela sabia que seu chi era uma mulher, não somente porque, em seu modo de ver as coisas, apenas uma mulher seria tão meticulosa em punir outra. Além disso, não he haviam dito tantas vezes em casa, em Ibuza, que seu chi era uma escravizada que havia sido forçada a morrer com sua senhora quando esta estava sendo enterrada? Assim, aquela escrava estava fazendo todo o possível para que a vida de Nnu Ego não passasse de uma sucessão de desastres (EMECHETA, 2008, p. 3-4). ${ }^{17}$
\end{abstract}

O excerto acima, parte do capítulo inicial do romance, ilustra o desespero de Nnu Ego após a morte de seu primeiro filho, criança gerada após inúmeras tentativas frustradas da protagonista de tornar-se mãe. Estabelece-se uma relação de causalidade direta entre a ação de seu chi, o seu deus pessoal (o "sopro vital” de cada ser, segundo a cultura nagô) ${ }^{18}$ e a "sucessão de desastres" que é a sua vida. À primeira vista, analisar esta relação poderia servir como um pretexto para compreender certos aspectos da cosmologia africana e das relações, muitas vezes liminares, entre os vivos e os mortos. Para além desta leitura, entretanto, Robolin (2004) chama

17 Tradução do trecho "[a]s she walked, pain and anger fought inside her; sometimes anger came to the fore, but the emotional pain always won. And that was what she wanted to end, very, very quickly. She would soon be there, she told herself. It would soon be over, right there under the deep water that ran below Carter Bridge. Then she would be able to seek out and meet her chi, her personal god, and she would ask her why she had punished her so. She knew her chi was a woman, not just because to her way of thinking only a woman would be so thorough in punishing another. Apart from that, had she not been told many times at home in Ibuza that her chi was a slave woman who had been forced to die with her mistress when the later was being buried? So the slave woman was making sure that Nnu Ego's own life was nothing but a catalogue of disasters (EMECHETA, 2008, p.3-4).

${ }^{18}$ Ver Theodoro (2008, p. 67).

Revista Graphos, vol. 21, n 2, 2019 | UFPB/PPGL | ISSN 1516-1536 
atenção para a crítica que Emecheta faz da maternidade ao associá-la à escravidão - algo do qual a protagonista acredita ser impossível de escapar, mesmo após a sua morte. Em certa medida, a maternidade como instituiçãa $o^{19}$ não poderia ser considerada como um gendered haunting? Uma constante assombração sobre a qual não se tem controle e da qual não há escapatória?

O que se observa muito claramente em The Joys of Motherhood é a problematização das consequências do colonialismo sobre a mulher nigeriana, que se vê forçada a um deslocamento indesejado da zona rural em que vive, se distanciando, portanto, das redes de apoio e solidariedade femininas que seriam possíveis em seu entorno, redes estas capazes de garantir o exercício de uma atividade econômica sem perda das relações familiares, e sem causar o abandono dos filhos à própria sorte. A experiência da maternidade, nesse contexto, dificilmente significaria empoderamento, uma vez que reduz as ações de Nnu Ego, limitando sua capacidade de ação a uma esfera apenas, a doméstica, quando, na realidade, sem a atuação econômica na dimensão pública, os seus filhos não sobreviveriam.

O sobrenatural também se faz presente em Um defeito de cor e altera não só os rumos tomados pela protagonista, mas as próprias percepções de Kehinde sobre muitos dos obstáculos que ela enfrenta ao longo de sua vida. A crença no destino e na ideia de que ele determinaria "o dia marcado no qual os seres devem voltar para o orum [plano espiritual] e abrange a personalidade do indivíduo, sua ocupação e sua sorte" ( THEODORO, 2008, p. 67), é um dos alicerces que sustentam Kehinde em duas de suas maiores perdas - quando Banjokô, seu primogênito, morre antes da adolescência, e quando ela é permanentemente separada de seu segundo filho, Omotunde, nascido livre, mas vendido como escravo pelo próprio pai.

\footnotetext{
Combinamos então que eu faria a viagem [para reencontrar o filho], mas sempre que estava ficando quase tudo certo, alguma coisa me impedia de ir. Alguma coisa não; hoje sei que foi o próprio destino, pois, se tivesse ido, saberia o que de verdade estava acontecendo com ela e provavelmente teria evitado o que aconteceu com você. Não sei se era o meu destino ou o seu que tinha de se cumprir, ou os dois juntos [...] (GONÇALVES, 2009, p. 629, grifo nosso).
}

Fincada na crença de que a separação entre ela e Omotunde aconteceria independente de suas ações ou desejos, uma vez que já estava determinada pelo próprio destino, a personagem diminui um pouco o peso da culpa que carrega. Desde o seu nascimento, Kehinde havia pressentido que o menino seria um $a b i k u^{20}$, e que, portanto, corria o risco de morrer de forma

\footnotetext{
${ }^{19}$ Aqui retomamos a distinção entre maternidade (instituição de controle e opressão patriarcal) e maternagem (agência e empoderamento).

${ }^{20}$ Sobre a presença de abikus e outros seres liminares em Um defeito de cor, ver Silva, 2017. Revista Graphos, vol. 21, n 2, 2019 | UFPB/PPGL | ISSN 1516-1536
} 
prematura. O que ela não imaginava é que, apesar de ser bem-sucedida em conseguir que os vínculos da criança com o plano terreno fossem fortalecidos, prolongando, assim, a sua existência no mundo dos vivos, a ruptura entre mãe e filho ocorreria por outros motivos. Contudo, ao refletir sobre sua trajetória, percebe que Omotunde tinha um caminho próprio a trilhar, desvinculado do seu. Ademais, o apoio que recebeu de várias figuras maternas fez com que essas separações tenham sido vivenciadas de forma menos traumática, aliviando, de certa forma, o sofrimento de Kehinde, ao contrário do que se observa na trajetória de Nnu Ego, cuja "teia familiar" é fragmentada a partir da dinâmica advinda da colonização. De maneira análoga, as fraturas e separações entre mães e filhos em Um defeito de cor, não devem ser consideradas apenas sob o prisma da cosmologia africana, e sim como uma encenação ou reverberação das rupturas causadas pela diáspora africana e pelo sistema de exploração escravagista.

\section{Concluindo: a maternidade e seus elos transnacionais}

Embora escrevam a partir de contextos e continentes distintos, as narrativas de Gonçalves e Emecheta parecem confluir para uma desconstrução da representação da maternidade e das práticas de maternagem. Evidenciam, portanto, um corpo materno negro que contesta e se contrapõe à subalternidade do patriarcado e da política de objetificação corporal, na medida em que articula a falibilidade de um modelo duplo de subserviência apoiado na escravidão, no caso da primeira, e perante uma sociedade em processo de descolonização, e em transformação de um modelo rural para o urbano, no caso específico de Emecheta. Embora em Um defeito de cor a protagonista Kehinde tenha resistido ativamente desde o momento em que foi capturada em África e trazida como escravizada ao Brasil, em The Joys of Motherhood, Nnu Ego, a personagem central, rebela-se tardiamente, ao final da narrativa. Dessa maneira, na medida que apresentam e representam outras visões acerca da maternidade negra e/ou afro-diaspórica, tais narrativas podem ser lidas a partir dos estudos de Patricia Hill Collins (2002) e de Andrea O'Reilly (2007; 2010) sobre a maternagem e maternidade como experiências de empoderamento e subversão.

\section{Referências}

ARAÚJO, Ana Lúcia. Public Memory of Slavery: victims and perpetrators in the South Atlantic. New York: Cambria Press, 2010.

BROWN-GUILLORY, Elizabeth. (Org.) Middle Passages and the Healing Place of History: migratin and identity. The Ohio State University Press, 2006. 
CARNEIRO, Sueli. Enegrecer o feminismo: a situação da mulher negra na América Latina a partir de uma perspectiva de gênero. Racismos contemporâneos. Rio de Janeiro: Takano Editora, v. 49, p. 49-58, 2003.

CHRISTIAN, Barbara. Black Feminist Criticism: perspectives on Black women writers. Oxford: Pergamon Press, 1985.

DAVIS, Angela. Women, Race and Class. 1981. New York: Vintage, 1983.

DAVIES, Carole Boyce; OGUNDIPE-LESLIE, Molara (Org.). Moving Beyond Boundaries: Black Women's Diasporas. Vol. 1. New York: New York University Press, 1995.

Black women, writing and identity: Migrations of the Subject. New York:

Routledge, 2003.

DAVIES, Carole Boyce.; GRAVES, Anne A. (ed.) Ngambika: Studies of Women in African Literature. Trenton: Africa World Press, 1986.

EMECHETA, Buchi. The Joys of Motherhood. England: Heinemann, 2008.

EVARISTO, Conceição. Gênero e etnia: uma escre (vivência) de dupla face. Mulheres no mundo, etnia, marginalidade e diáspora, p. 201-212, 2005.

FLAX, Jane. The conflict between nurturance and autonomy in mother-daughter relationships and within feminism. Feminist Studies, v. 4, n. 2, p. 171-189, 1978.

GONÇALVES, Ana Maria. Um defeito de cor. Rio de Janeiro: Record, 2009.

HILL COLLINS, Patricia. Black Feminist Thought, Routledge, 2002.

HOOKS, Bell. Ain't I a Woman: black women and feminism. Boston: South End, 1992. Feminist Theory: from margin to center. Boston: South End, 1984.

MELO NASCIMENTO, Gizelda. Grandes mães, reais senhoras. In: NASCIMENTO, Elisa Larkin (Ed.). Guerreiras de natureza: mulher negra, religiosidade e ambiente. São Paulo: Grupo Editorial Summus, 2008.

MENDES, M. Elizabeth P. S. Maior. O corpo materno em Without a Name e Butterfly Burning, de Yvonne Vera: tensões, transgressões e resistências. Tese (Doutorado em Letras) - Programa de Pós-Graduação em Letras, Universidade Federal da Paraíba. João Pessoa, 2017.

NNAEMEKA, Obioma. The Politics of (M)Othering: Womanhood, Identity and Resistance in African Literature London: Routledge, 1997.

OKIN, Susan Moller. Gender, the Public and the Private. Revista Estudos Feministas, v. 16, n. 2, p. 305-332, 2008.

O'REILLY, Andrea. Stories to live by: maternal literatures and motherhood studies. In: PODNIEKS, Elizabeth; O'REILLY, Andrea (Ed.). Textual Mothers/Maternal Texts: Motherhood in Contemporary Women's Literatures. Wilfrid Laurier Univ. Press, 2010. 
. Maternal Theories: Essential Readings. Toronto: Demeter Press, 2007.

OYEWUMI, Oyeronké. Abiyamo: theorizing African motherhood. Jenda, a Journal of Culture and African Women Studies, Issue 4, 1999.

RICH, Adrienne. Of Woman born: Motherhood as experience and institution. New York: WW Norton \& Company, 1995.

ROBOLIN, Stéphane. Gendered Hauntings: The Joys of Motherhood, Interpretive Acts, and Postcolonial Theory. Research in African Literatures, p. 76-92, 2004.

SILVA, Danielle de Luna e. Maternagens na diáspora amefricana: resistência e liminaridade em Amada, Compaixão e Um defeito de cor. Tese (Doutorado em Letras) Programa de Pós-Graduação em Letras, Universidade Federal da Paraíba. João Pessoa, 2017.

SPILLERS, Hortense J. Mama's Baby, Papa's Maybe. In: NAPIER, Winston (Org.) African American Literary Theory: A Reader. New York: NYU, 2000.

THEODORO, Helena. Religiões afro-brasileiras. In: NASCIMENTO, Elisa Larkin (Org.) Guerreiras de natureza: mulher negra, religiosidade e ambiente. São Paulo: Selo Negro, 2008.

Recebido em: 30/09/2019 Aceito para publicação em: 26/11/2019 